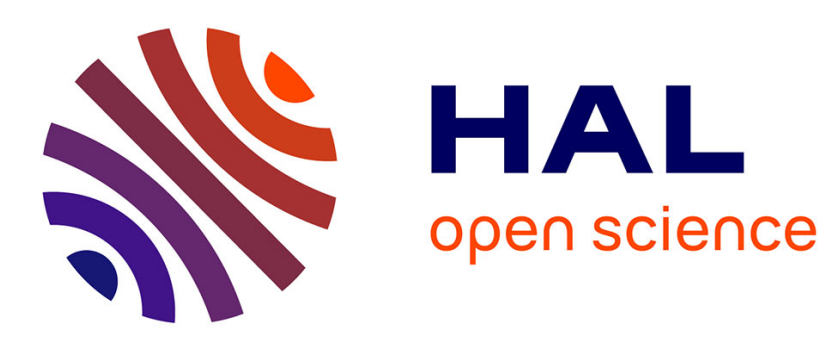

\title{
A semi-mobile flash dryer/calciner unit to manufacture pozzolana from raw clay soils - application to soil stabilisation
}

\author{
Sylvain Salvador, O Pons
}

\section{To cite this version:}

Sylvain Salvador, O Pons. A semi-mobile flash dryer/calciner unit to manufacture pozzolana from raw clay soils - application to soil stabilisation. Construction and Building Materials, 2000, 14 (2), pp.109-117. 10.1016/S0950-0618(00)00005-2 . hal-01697286

\section{HAL Id: hal-01697286 \\ https://hal.science/hal-01697286}

Submitted on 23 Mar 2018

HAL is a multi-disciplinary open access archive for the deposit and dissemination of scientific research documents, whether they are published or not. The documents may come from teaching and research institutions in France or abroad, or from public or private research centers.
L'archive ouverte pluridisciplinaire HAL, est destinée au dépôt et à la diffusion de documents scientifiques de niveau recherche, publiés ou non, émanant des établissements d'enseignement et de recherche français ou étrangers, des laboratoires publics ou privés. 


\title{
A semi-mobile flash dryer/calciner unit to manufacture pozzolana from raw clay soils - application to soil stabilisation
}

\author{
S. Salvador ${ }^{\mathrm{a}, *}$, O. Pons ${ }^{\mathrm{b}}$ \\ ${ }^{a}$ Ecole des Mines d'Albi Carmaux, Campus Jarlard, 81013 Albi CT Cedex 09, France \\ ${ }^{\mathrm{b}}$ Entreprise MALET, 30 Avenue de Larrieu, 31081 Toulouse Cedex France
}

\begin{abstract}
The use of hydraulic binders in the construction of durable housing or roads in developing countries is an efficient technique, for which there is a demand at various times and in dispersed places throughout the world. The problem of the need for these perishable products could be resolved by the local production of pozzolana from clay soils using a semi-mobile dryer/calciner plant. By means of theoretical modelling of the thermochemical phenomena involved, and different small-scale pilot tests, we have developed a flash calcination process to this end. The Malet company has designed and built an industrial $800 \mathrm{~kg} / \mathrm{h}$ production unit (International patent PCT/FR98/01149-Publication No. WO98/55418). It can be dismantled, moved over land (road network) and sea, and assembled within a few days. Once installed, it can be in production in $1 \mathrm{~h}$. We have turned to our advantage the various benefits of the flash technique: the construction is light and compact, there is no need for grinding materials after calcination, and short materials residence time inside the unit results in short process response time and reduced start and shutdown operations duration. We describe the plant here, giving details of establishing the mass/thermal balance, the design of the gas and materials circuits, the process control system, and the construction and packaging. The plant is largely composed of a drying cyclone, a hammer mill, a preheating cyclone, a multi-burner combustion chamber with its separator cyclone and three cooling cyclones. We then compare the performances of the hydraulic binder elaborated from the pozzolana out of the unit plus lime, with those of an ordinary Portland cement. (c) 2000 Elsevier Science Ltd. All rights reserved.
\end{abstract}

Keywords: Flash calciner; Pozzolana; Hydraulic binder; Mobile plant; Building materials

\section{Introduction}

The durable construction of housing or roads in developing countries suffers from the high cost of building materials. When these materials are extracted from a quarry (stones, granulates) or industrially produced (hollow bricks), they have to be carried to the work place. Given the considerable weight involved,

\footnotetext{
* Corresponding author. Tel.: + 33-5-63-49-31-27; fax: +33-5-63-
} 49-30-99. and the long distances to be covered, transport is often by far the more expensive operation, particularly in developing countries where the coated road network is insufficient, and track traffic very slow.

The use of compacted local soils has proved to be a competitive solution, and additionally a durable one, provided materials are stabilised by use of an hydraulic binder. Lateritic soils are then extracted and mixed with a small quantity of powdered dry binder (1-10\% of dry soil wt.) before being compacted. After curing (1-6 weeks), raw materials have acquired a mechanical strength and above all a water insensitivity they did not 
have before, which make them usable in building houses with several floors on the one hand, and low to high traffic roads as well as tracks on the other. The drawback of this technique is again the cost of the binder when transport is included. Beyond the carriage cost that doubles or triples the production cost, these products are perishable due to their high water reactivity (cement or lime) or air carbon dioxide affinity (lime). Their long carriage from the place of production to the building site (boat plus lorry) and additional storage in a wet atmosphere before use, result in considerable wasted quantities.

The local production of hydraulic binders of the type 'pozzolana + lime' is an answer to this problem. Pozzolana (representing $60-90 \%$ of the binder) is then manufactured from a clay soil that is calcined at moderate temperatures $\left(500-950^{\circ} \mathrm{C}\right)$.

In order to meet a local small demand, small capacity installations have been developed, using different heaters as vertical shaft furnaces, rotary kilns or fluidised beds $[1,2]$. Looking closely at total production costs of binders with such installations clearly shows that only a heavy utilisation sufficiently reduces the paying off cost to preserve cost effectiveness of the project. In the case of small and punctual demand (in place and in time), a 'mobile' installation is indicated. This mobility (meaning that the plant can be moved from one site to another) requires several characteristics:

1. the size and the weight of each element have to satisfy road transport requirements. All equipment must be able to withstand, on a mechanical point of view, road transport;

2. moving the plant from site to site, that includes stopping, disassembling, carrying, reassembling and starting, has to remain easy and quick;

3. no civil engineering must be required to install the plant.

Using flash calcination enables all these criteria to be met. Through theoretical modelling of thermochemical phenomena involved [3-5], and different small scale pilot tests (with capacities ranging from 1 to $300 \mathrm{~kg} / \mathrm{h} \mathrm{[6-8]),} \mathrm{we} \mathrm{have} \mathrm{adapted} \mathrm{this} \mathrm{technique} \mathrm{to} \mathrm{the}$ production of pozzolana from clay soils, and built a $800-\mathrm{kg} / \mathrm{h}$ production unit we describe below.

\section{The flash calcination technique}

With flash heat treatment, materials are processed in the physical state of a powder. This powder, when injected in a gas flow (air or smoke) that supplies both transport energy and heat exchange, can be dried,

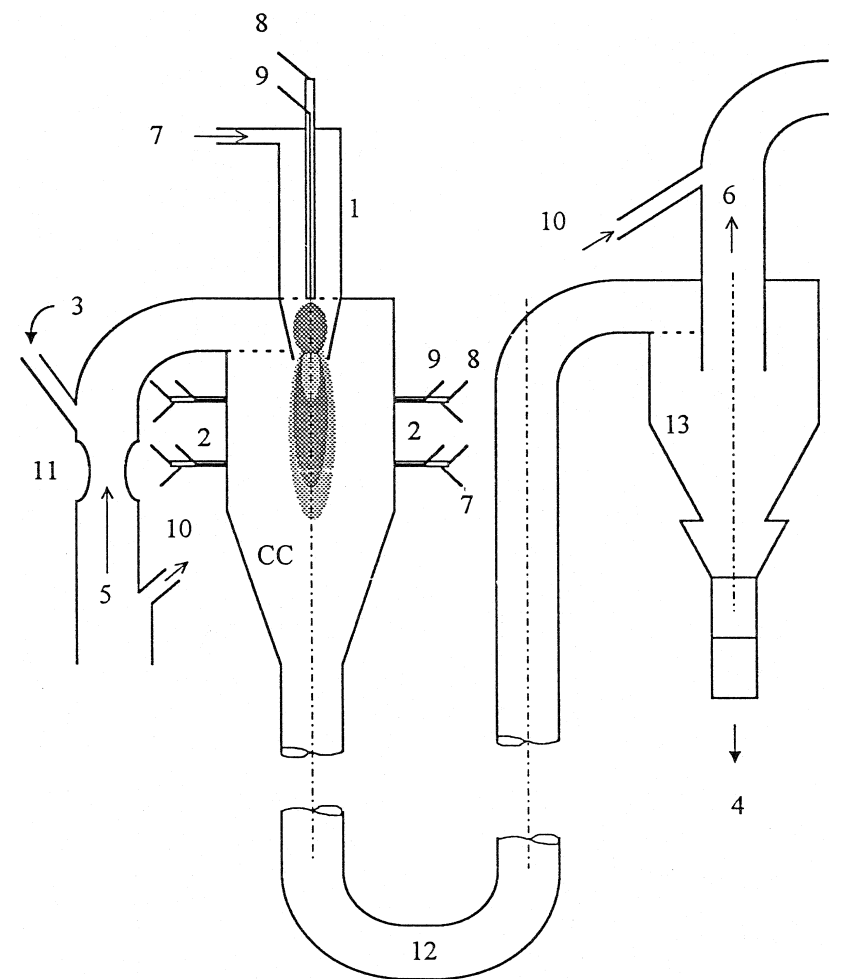

Fig. 1. Description of the calcination zone: (1) axial burner; (2) six radial burners; (3) preheated materials; (4) calcined powder; (5) secondary air; (6) hot gases; (7) primary air; (8) spraying air; (9) fuel; (10) by-passed air; (11) venturi; (12) swan-neck pipe; (13) separator cyclone; (CC) combustion chamber.

heated or cooled down depending on the initial gas and particle temperatures.

The design of the complete calciner unit is better understood by looking first at its heart: the combustion chamber (CC). Powdered materials suspended in the carrying air enter the chamber in which fuel is burnt, supplying the required thermal energy (see Fig. 1). The following cyclone (SC) assures separation of the two streams: smoke and particles. The residence time at high temperature in the calcining zone (CC, SC and the swan-neck pipe) induces the dehydroxylation of clay particles, converting them into pozzolana. The sensible heat of the two streams leaving the calcining zone is recovered by cooling down materials in cooling cyclones that preheat air to the $\mathrm{CC}$ on the one hand, and by drying and preheating materials in additional cyclones before they enter the $\mathrm{CC}$, recovering sensible heat from the smoke stream on the other hand. This leads to the traditional cyclone assembly in which materials and gas are globally flowing counter-current through the assembly, and locally concurrent inside each heat contactor (cyclone plus gas duct).

Before entering into design details, several deciding factors for the adoption of this technique in manufacturing pozzolana should be mentioned: 
1. at the beginning of the process, raw materials can be dried and disintegrated to the required fineness (typically $80 \%<80 \mu \mathrm{m}$ ) using very low amounts of mechanical energy (less than $2 \mathrm{kWh} / \mathrm{t}$ ). The equipment for this purpose is therefore much more simple and light than the grinders (ball mill) following pellet calcination in traditional processes (these calcined pellets are actually as hard as brick). This was the basic reason for choosing flash calcination.

2. Provided heat treatment is achieved on powdered materials, the handling through the unit is always pneumatic, and only boiler-made equipment is required. The whole construction is thus light, and does not need any civil engineering foundations, which makes it suitable for semi-mobile use. The lack of heavy moving parts also results in a high dependability unit.

3. As inferred from the term flash, the heat treatment duration is very short, reduced to several seconds or tenths of a second [5,7]. There is then, at a given time, only a little quantity of material being processed inside the plant (several $\mathrm{kg}$ for a 800 $\mathrm{kg} / \mathrm{h}$ production). This specifically brings numerous advantages:

- it leaves the 'light construction' assumption possible;

- very few materials are wasted during transient phases of stopping and emptying the unit, as well as during starting. Additionally, it takes less than $1 \mathrm{~h}$ to start production or stop the unit.

- as far as process control is concerned, this small amount of materials enables very quick changes of processing parameters, and a very precise control of the calcining temperature.

\section{Thermal balance}

Raw clay soils will undergo two reactions crossing the unit (see Fig. 2). First drying will take out the $0-12 \%$ (of dry wt.) moisture. The second reaction is the dehydroxylation of clay particles that usually occurs at temperatures ranging from 500 to $950^{\circ} \mathrm{C}$, and leads to an amorphous phase, called pozzolana, resulting in high lime reactivity. The loss on ignition (LOI) of a dry product is typically $10-14 \%$. A third undesirable reaction will occur if the temperature happens to be above $950^{\circ} \mathrm{C}$, and lead to recrystallised phases (mullite and cristoballite) offering very poor lime reactivity [9].

A typical mass balance could be as follows: 1.25 tons of raw soil containing $10 \%$ moisture will be dried to give 1.14 tons of dry soil presenting a $12 \%$ LOI, and calcined to produce 1 ton of pozzolana. When calculating the materials' flow rates inside each part of the unit, the collecting efficiency of each cyclone was additionally taken into account.

The general method used was a classical enthalpy balance for each cyclone, to calculate the materials and gas mass flow rates inside each one. Materials and gas sensible heat, chemical reaction endothermic, thermal losses at outside surfaces (to which special care must be paid when designing small scale units [8] and combustion energy supply were taken into account.

The thermal balance establishment phases are better understood by considering again the calcination zone as the heart of the unit. This zone is composed of the combustion chamber, the swan-neck pipe, and the separator cyclone, SC (see Fig. 1); it is in this zone alone that the dehydroxylation of the clay will be achieved. Fuel will be supplied to the burners in order to reach the calcination temperature that is required, typically $700^{\circ} \mathrm{C}$. Hot gases on the one hand and calcined materials on the other will exit the $\mathrm{CE}$ cyclone at approximately similar temperatures. Aiming to recover sensible heat of these two streams, gases will be used to preheat incoming materials, and materials to preheat air, before they enter the calcining zone.

The greater the number of cyclones used to cool down materials, the higher the recovering efficiency and the easier the handling of finished materials. On the other hand, numerous cyclones will result in a high tower, and in high-pressure drop to be supplied by the extractor fan, resulting in high electrical energy requirement. The optimum number of cyclones was determined to be three, leading to output materials temperatures of approximately $200^{\circ} \mathrm{C}$. The reasoning is valid as far as the materials preheating is concerned. The additional constraints are that gas should not be too cold (to exclude condensation phenomena), and not to hot for the bag filter to survive the temperature. In this reasoning, the drying stage can be considered as a preheating stage, in the sense that it is a way to recover thermal energy from the smoke. Two cyclones (drier and PC) were here necessary.

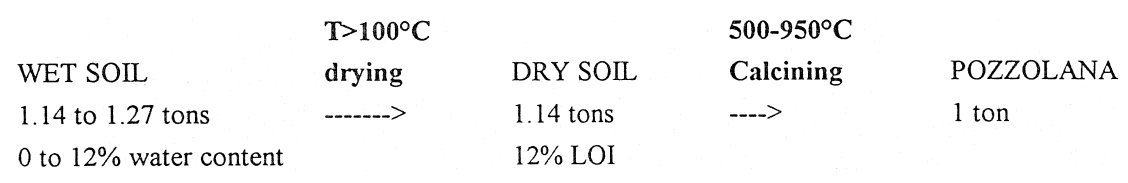

Fig. 2. Reaction sequences of a raw wet clay soil during drying and calcining - mass balance. 
The combustion air flow required to burn fuel oil in the calcining zone (for classical residual oxygen content in smoke) is smaller than the air flow required to efficiently cool down materials; a bypass duct was therefore used. Part of the air out of the cooler cyclones will thus not cross the calcining zone, which additionally enables tuning the combustion parameters (via air flow adjustment) without modifying the total air flow, by balancing the flow between the combustion chamber and the bypass. The global flow-sheet of the unit is given in Fig. 3.

\section{Technological design}

\subsection{Combustion chamber}

Cement plant precalciners use various examples of combustion chamber designs, with sophisticated introductions of fuel, air and materials. Nevertheless, regarding the high variability in properties of materials to be processed and the small size of our unit, we have designed a reactor of simple geometry. It is an axisymmetric volume composed of a cylinder and a reduction cone at its bottom part. Materials and carrying air enter tangentially the upper part of the chamber.

In a first combustion mode, an axial top flame directed downward supplies energy to gas and materials swirling around. The flame is fastened on the burner via a pre-mixing cone receiving primary combustion air that stabilises a high temperature spear.

Homogenous temperature distribution inside the $\mathrm{CC}$ will lead to a better quality product, by minimising the over calcined product rate. With this in mind, we have fitted the combustion chamber with additional burners to operate a second combustion mode. Six radial burners supplying each one-sixth of the required thermal power, can spray fuel all around the CC, establishing a diffuse combustion of the three phase mix: air plus fuel plus materials.

Whatever the combustion mode used, three types of combustion air are supplied to the seven commercial burners:

- spraying air: this air, as well as fuel, is supplied at pressures between 2 and 7 bar. The thermal power of the furnace is controlled via this pressure that is regulated in an intermediary pressurised small capacity fuel tank.

- primary air (supplied through the stabilisation cone of the axial burner, and through small axial holes around each radial burner fuel injector) that is drawn in by the low internal pressure of the CC.

- secondary air, carrying materials.

Depending on the processing parameters, the combustion air excess $[(A \mathrm{t}-A \mathrm{~s}) / A \mathrm{~s}, A \mathrm{t}$ : total air; $A \mathrm{~s}$ : stoichiometric air] can vary between 0.3 and 0.8 . The

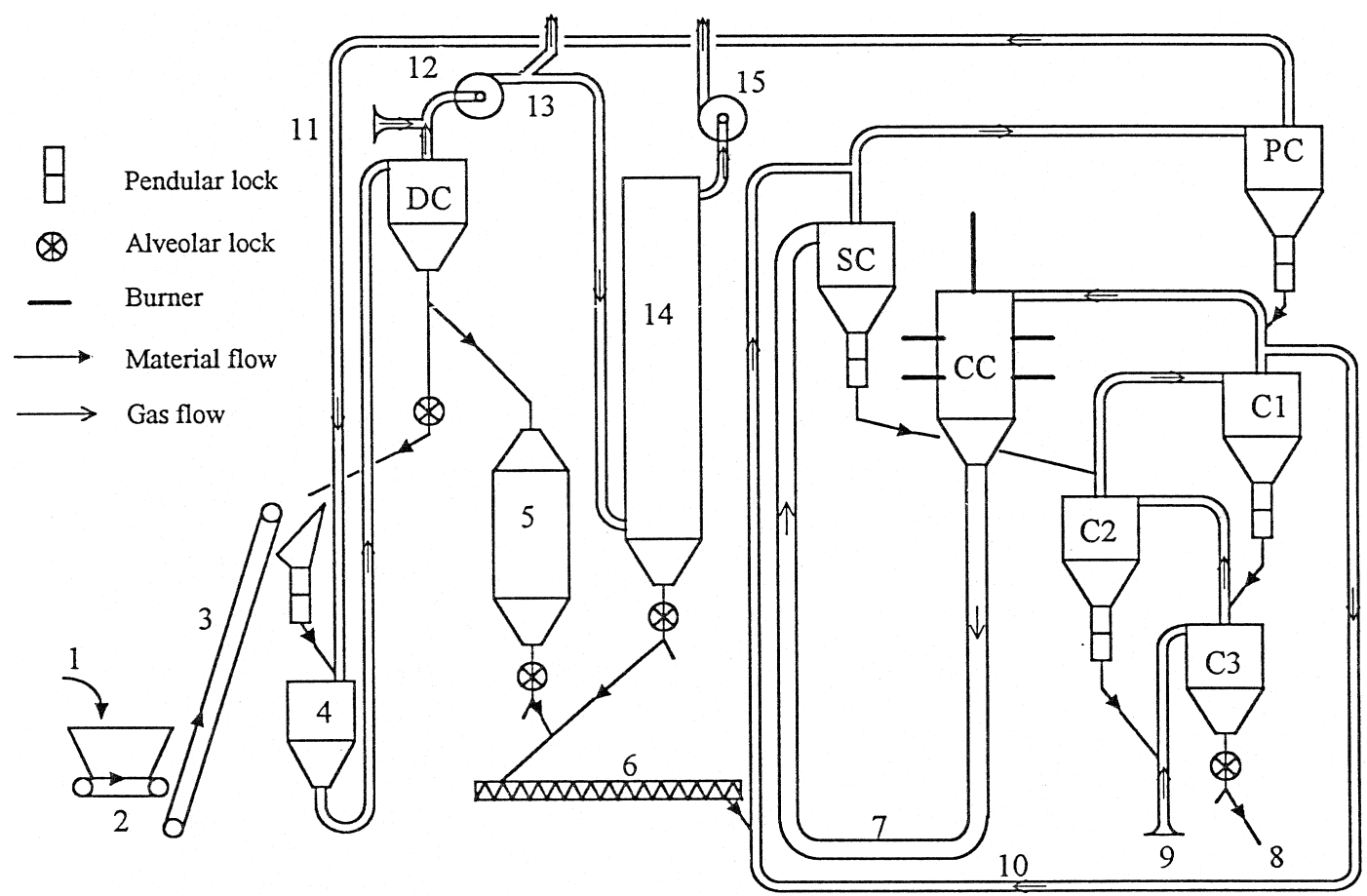

Fig. 3. Flow sheet of the MALET industrial flash dryer/calciner: (1) raw materials; (2) extractor belt; (3) conveyor belt; (4) hammer mill; (5) dry product silo; (6) screw conveyor; (7) swan-neck pipe (8) final product; (9) principal air flow; (10) by-pass; (11) air dilution; (12) exhauster (13) smoke shunter; (14) bag filter; (15) filter fan; (DC) dryer cyclone; (SC) separator cyclone; (C1, C2, C3) cooling cyclones; (PC) pre-heater cyclone; (CC) combustion chamber. 
primary air rate $(A \mathrm{p} / A \mathrm{~s}, A \mathrm{p}$ : primary air plus spraying air) is maintained around 0.25 .

Thermal power density higher than $1100 \mathrm{~kW} / \mathrm{m}^{3}$ can be generated inside the chamber. This high value [8] is at the origin of a very compact combustion chamber, enabling a high production capacity in a light and low volume reactor.

The CC is a refractory steel shell with inside dense refractory concrete coating and outside silica/alumina wool insulation. The whole concrete temperature thus remains close to the inside gas and particle temperature; this is a limiting factor for agglomeration phenomena.

\subsection{Aerolic circuit}

The velocity of gases is chosen to ensure:

- non-deposition of solid particles, which determines minimum gas velocities and special local design;

- sufficient residence time of particles in gas on the one hand, and low pressure drop throughout the unit on the other hand, which determines maximum gas velocities.

From the gas flow rates determined by establishing the thermal balance of the unit, and velocities determined to fulfil the above criteria (that lead to gas velocities in the range $11-38 \mathrm{~m} / \mathrm{s}$ ), the gas duct diameters have been calculated. They range between 110 and $300 \mathrm{~mm}$.

A main exhauster fan sucks the air through the whole unit, but through the bag filter, whose pressure drop is compensated with an additional specific fan.

The hammer mill is equipped with a large 2-mm perforations grid at its bottom periphery so that no obstruction occurs and disturbs the main air flow.

The pressure inside the unit is always less than atmospheric. Operating security is increased: should one part be unintentionally opened or broken, fresh air will just be sucked in, where a pressurised unit would blow hot gas and materials out. This also facilitates supplying primary air to the seven fuel burners and to the smoke dilution utilising suction at any aperture. To ensure no air circulation at the bottom of each cyclone, a lock is installed.

The air velocity is increased:

1. Inside the bottom elbows so no deposit will occur. Typical values of $11-15 \mathrm{~m} / \mathrm{s}$ inside gas ducts are progressively increased to $35 \mathrm{~m} / \mathrm{s}$ at the very bottom, and decreased before the exit of the elbow. Specially designed wearing soles were installed, enabling easy replacement if necessary.

2. In vertical ducts with particle laden gas streams using a venturi, to prevent any fall of solid materials into a cyclone chimney.

The temperature relaxation time for particles of the considered granularity during suspension conveying has been shown to be in the order of one-tenth of a second up to $1 \mathrm{~s}$ for the biggest particles [5]. When gas velocity is approximately $12 \mathrm{~m} / \mathrm{s}$, the duct length has to approach $12 \mathrm{~m}$. This is why ducts for gases and materials before entering a cooling cyclone and the drying tube were artificially lengthened to 5-9 m. With special attention, the swan-neck pipe was lengthened to $15 \mathrm{~m}$. This was one additional difficulty in designing a small capacity installation.

The main air flow rate, which typically ranges between 500 and $600 \mathrm{~m}^{3} / \mathrm{h}$ (standard conditions), is controlled by obstructing the main air entrance using a butterfly valve, while the exhauster fan always rotates at its nominal speed. Distribution of air between the combustion chamber and the bypass is balanced via a butterfly valve inside the bypass. A dilution valve allows fresh air to enter and to mix with smoke out of the DC to the $36-\mathrm{m}^{2}$ filter, when their temperature is above $140^{\circ} \mathrm{C}$.

\subsection{Materials circuit}

As far as possible, the materials transport throughout the unit has been designed using pneumatic conveying of materials suspended in gases on the one hand, and natural gravity fall of powder flow on the other. These two transport mechanisms, provided inside static ducts, result in the simplest design, low weight and high reliability.

The design of each part of the unit was thought out bearing in mind that the material flow is to be maintained at a regular value. Solid material is indeed the principal thermal load of the process, noticeably inside the dryer and the calcining zone where endothermic reactions occur. Should this flow rate decrease or stop, the inside temperature of the $\mathrm{CC}$ will increase within fractions of a second to high values. We have shown overcalcination can then occur within the same time scale [9], leading to very poor quality product. On the other hand, a sudden material flow increase (releasing packed deposits of materials for instance) will result in low calcining temperatures, which results in partially dehydroxylated materials. This essential material flow regularity was obtained thanks to:

1. the addition of a dry product silo, out of which dried powdered materials can be extracted and sent to the calciner with high regularity, since the flow is no longer affected by fluctuations resulting from the hammer mill grid crossing. This silo additionally enables contemporaneous processing of dif- 
ferent material flows inside the dryer and inside the calciner, which facilitates the control of transient operations such as starting and stopping the unit;

2. the alveolar locks, that were chosen to be of the helicoidal cell type. The pendular locks, used whenever the temperature is too high for a rotating lock (e.g. above $200^{\circ} \mathrm{C}$ ), are double and electrical motor actuated at a frequency of $1 / \mathrm{s}$. The approximate $220 \mathrm{~g}$ packets out of each opening (at $800 \mathrm{~kg} / \mathrm{h}$ production) are supposed to be dispersed when entering a gas duct. Their entrance is $150 \times 150$ $\mathrm{mm}$ (i.e. much bigger than required in theory) to avoid vaulting;

3. the cyclones which are special 'new generation' high collecting efficiency ones; the tangential entrance is designed to prevent the formation of powder packs.

The raw soil is disintegrated by the loader, that feeds the $2 \mathrm{~m}^{3}$ raw materials hopper, with less than $30-\mathrm{mm}$ diameter lumps. A first slow conveyer belt extracts a large section material vein (regarding lumps size). A second quick belt (to reduce response time) takes the $1.25 \mathrm{t} / \mathrm{h}$ up into the hammer mill. Materials represent the thermal load of the grinder that also acts as a heat contactor, provided it is also fed with the smoke out of the PC at typically $400^{\circ} \mathrm{C}$. Having crossed the grid, powdered materials are dried at a temperature of approximately $140^{\circ} \mathrm{C}$ during pneumatic conveying inside the drier tube and cyclone. Should materials be still wet when leaving the cyclone, part of the flow can be recycled via an overfed alveolar lock extractor. Products out of the dry product silo are mixed with fine particles out of the filter. Because of geometric limitations (no sufficient height to use natural fall) we were forced to use a screw conveyor to feed the powder into the bypass that is then used as a lift. The powder crosses the PC cyclone, the CC and the swan-neck pipe, the SC cyclone and the three cooler cyclones. Products out of C3 can be pneumatically conveyed into the finished product silo.

Fine particles are of particular interest regarding the use of calcined products as pozzolanic materials: their high specific surface leads to highly reactive products. It should be noted that, since each cyclone has a collecting efficiency of $85-95 \%$, fine particles continuously escape cyclones with exhaust gases, to be collected (or not, from a statistical point of view) by the following cyclone. This results in a fine particle concentration increase inside the unit.

\section{Process control}

The installation is heavily instrumented, regarding temperature, pressure and gas flow measurements at numerous points.

Measurements on powdered materials is much more delicate. Flow rates are known from the calibration of the extractor conveyor belt speed as far as raw soil flow is concerned, and from the calibration of rotating locks for dry products. Temperatures are not measured (except inside the dry product silo) since no measurement point with continuous powdered materials flow could be guaranteed. The powdered material temperature is nevertheless well estimated assuming temperature steady-state is established between materials and gas (whose temperature is measured) at the output of each cyclone. The parameters of a run are continuously recorded on paper.

The unit is fully operated from the control cabin. Start or stop sequences, as well as security tests, can be automatically managed by an automaton. The high electric power cupboard is located inside the unit structure, to minimise high power network length and number of connectors.

The two temperatures to be set constant (e.g. calcination temperature and smoke temperature at filter entrance) are tuned via a PID controller for each one.

\section{Construction}

The whole shell of cyclones, ducts and pendular locks was made of ordinary steel whenever the inside temperature was less than $200^{\circ} \mathrm{C}$, of stainless steel for temperatures between 200 and $600^{\circ} \mathrm{C}$, and of refractory steel for higher temperatures. Steel thickness was 3 or $4 \mathrm{~mm}$, and could be increased to 6 or $8 \mathrm{~mm}$ for parts heavily subjected to abrasion by materials. The outside of the shell is insulated first with a silica/alumina 50-mm thick wool, and additional rock wool, resulting in $50-150 \mathrm{~mm}$ total thickness depending on the shell temperature. The locks, valves, and other heat sensitive parts were not insulated. In order to minimise the unit weight, only the combustion chamber was internally protected with a refractory concrete layer.

Equipment is supported on five different levels. Anchor clips are bolted on the main frame as far as heavy equipment is concerned, and sliding devices plus 14 (stainless steel multi-curve with inside protecting tube) expansion joints are used to accept thermal expansions. The propagation of mechanical vibrations from the grinder is limited by two expansion joints located on the entrance and at the exit ducts.

\section{Packaging}

In the main truck, shown on Fig. 4, all the equipment represented in the flowsheet (excluding those listed 


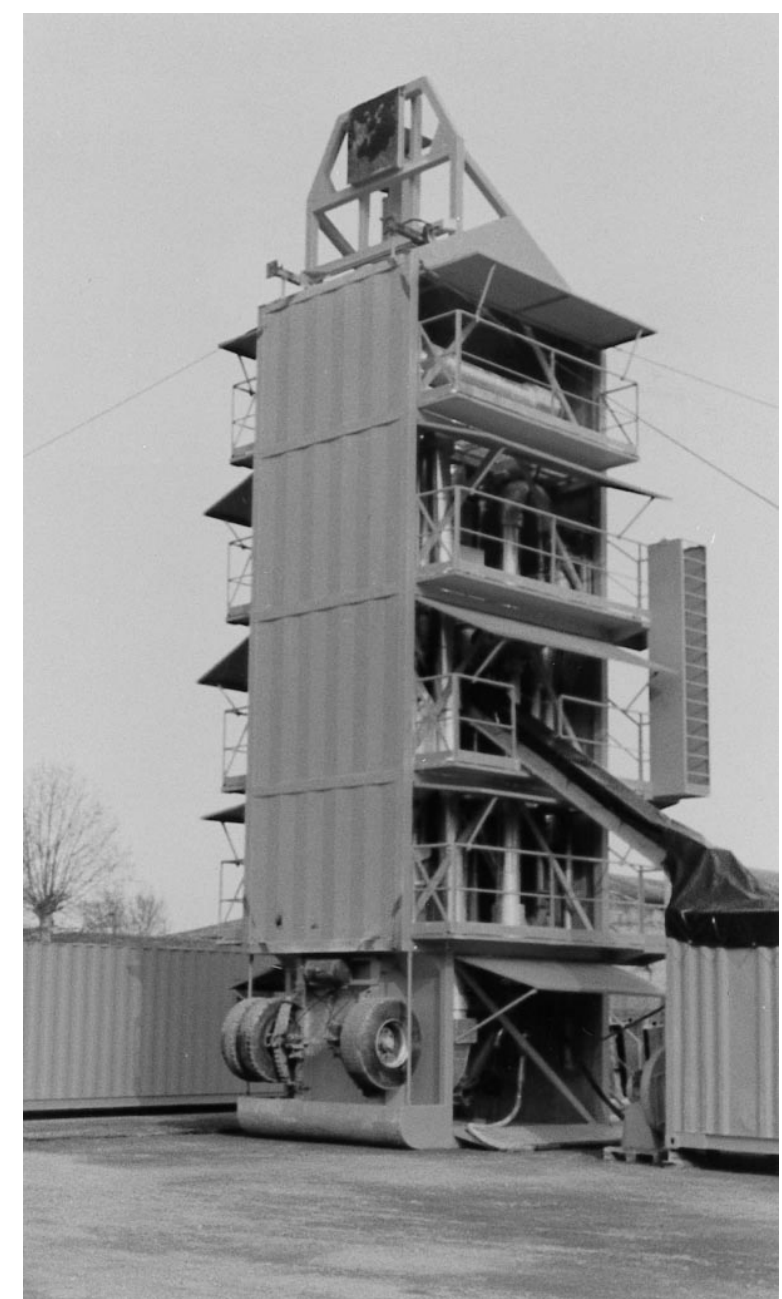

Fig. 4. Photograph of the main truck.

above) are installed. This $14.5-\mathrm{m}$ long, 3-m large and 4.5-m high truck is equipped with a single axle. Its total weight of 23 metric tons is roughly divided into one-half for equipment and the other half for support structure. During carrying, this truck is totally closed with steps and weatherboard panels that can be shut. When arriving on a site, stairs are bolted on the truck and panels opened before it is stood up. As designed today, erection is assured by a 90-ton capacity crane that is able to lift the truck above the ground. Other devices such as winches or hydraulic jacks can be used for this purpose. The tower is stabilised with three mooring lines despite the fact that it can withstand the strongest winds without the lines.

A 20-foot standard container shelters the generator, the air compressor and fuel tank. It should be noted that all of them are fed with domestic fuel oil: it is the only energy source of the unit. Electricity will be advantageously supplied by a network whenever possible. A second 20-foot standard container supports the raw materials hopper and extractor belt, plus the conveyor belt after dismantling during transportation. The con- trol cabin, a repair shop, and storage for the stairs (during transport) are located in an additional 40-foot container.

\section{Production capacity — energy consumption}

The unit was first successfully operated with a kaolinite raw clay as the calibration product. Steady air and material flow rates were set with calcining temperatures that could range between 500 and $900^{\circ} \mathrm{C}$.

The product granularity is to be set by adjusting the hammer mill rotation (500-1000 rev./min). It actually takes less than $1 \mathrm{~h}$ to start production.

The unit was operated by two people during tests, and only one during regular production.

The total fuel consumption was $35 \mathrm{l} / \mathrm{h}$ at $800 \mathrm{~kg} / \mathrm{h}$ pozzolana production. An additional electrical power of $55 \mathrm{~kW}$ is to be supplied.

Table 1 shows typical properties of the dried product (inside the dry product silo) and of the (flash) calcined product (final product). Typical properties of the same kaolinite after a soak calcination (fixed bed in an electrical furnace) are given for comparison. The particles density (measured from pycnometer tests) has decreased during the flash calcination, and not during a soak calcination. This behaviour of clay has already been observed at the laboratory scale by Davies [3]. The specific surface of particles (from BET measurements) appears to remain approximately the same after drying and after calcination, with a slight increase for the case of a flash calcination. The water absorption capacity of the calcined products has been measured in terms of the mass increase of particles when stored in a water saturated air atmosphere. Flash calcined kaolinite exhibits a significantly higher absorption capacity than the soak calcined products.

Daily 24-h production is 19.2 metric tons of pozzolana, which is equivalent to 27 tons of binder (after mixing with lime). This enables the stabilisation of 900 $\mathrm{m}^{2}$ of a road or track (on a $25-\mathrm{cm}$ depth, with $6 \%$ in

Table 1

Typical properties of a French kaolinite after drying and after flash calcination in the unit ${ }^{\mathrm{a}}$

\begin{tabular}{llll}
\hline & $\begin{array}{l}\text { Dried } \\
\text { product }\end{array}$ & $\begin{array}{l}\text { Flash calcined } \\
\text { product }\end{array}$ & $\begin{array}{l}\text { Soak calcined } \\
\text { product }\end{array}$ \\
\hline $\begin{array}{l}\text { Density of particles } \\
\text { Water absorption } \\
\text { capacity }\end{array}$ & 2.58 & 2.30 & 2.60 \\
$\begin{array}{c}\text { Specific surface } \\
\left(\mathrm{m}^{2} / \mathrm{g}\right)\end{array}$ & 18.8 & $19.0 \%$ & $7.8 \%$ \\
\hline
\end{tabular}

${ }^{\text {a }}$ Properties of the same kaolinite after a soak calcination are given for comparison. 
mass of binder), or the stabilisation of clay soil bricks to build $750 \mathrm{~m}^{2}$ of a $30-\mathrm{cm}$ thick building wall.

This unit is, as far as we know, the smallest multicyclone flash calciner that can be industrially exploited. The design of higher production capacities would make it closer (in size) to actually operated flash calciners, so should not lead to any additional difficulty. Such higher production capacity units should nevertheless be divided into more numerous containers in order to fulfil road traffic specifications.

\section{Performances of the pozzolana + lime binder}

Extensive work has been produced to compare the pozzolanic properties of soak calcined clays (kaolinite, montmorillonite, natural clay soil) and of flash calcined clays from laboratory or pilot scale tests [10]. We give below the performances of the pozzolana out of the unit, for soil stabilisation or soil-brick elaboration applications.

A pozzolana + lime binder (PLB) is elaborated by mixing $70 \%$ of pozzolana with $30 \%$ of lime (calcium monoxide). The pozzolana was elaborated from a natural lateritic soil from Madagascar (76\% kaolinite, $11 \%$ ematite, $4 \%$ quartz, $3.1 \%$ gibbsite and $0.4 \%$ illite). In this section, we give as typical binder performances, a comparison between standard Californian Bearing Ratio (CBR) and compressive strength of soils alternatively treated with $6 \%$ PLB and $4 \%$ ordinary Portland cement (OPC).

A natural clay soil was first used as the raw material to be stabilised by addition of an hydraulic binder. Fig. 5 shows values of the Immediate CBR (CBR-I) as well as CBR after 4 days of immersion in water at $20^{\circ} \mathrm{C}$

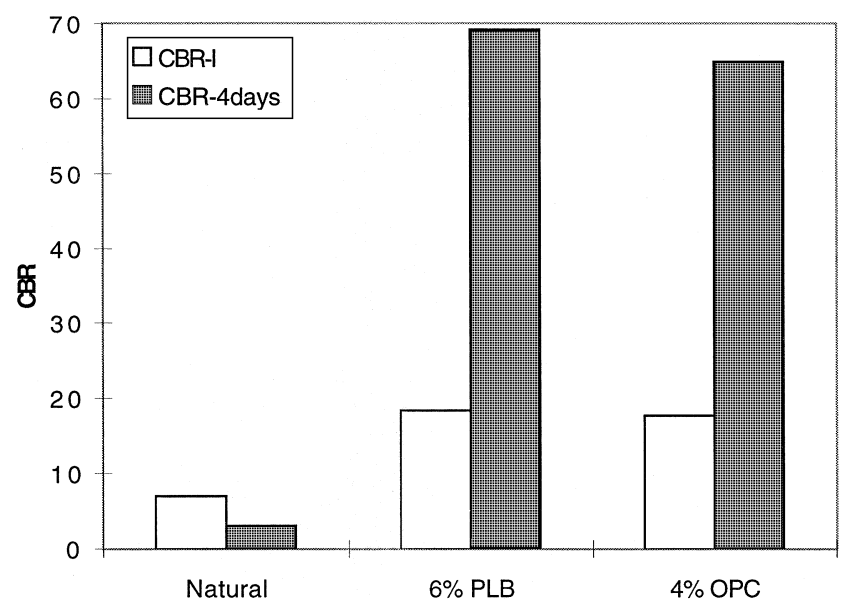

Fig. 5. Immediate Californian Bearing Ratio (CBR-I) and Californian Bearing Ratio after 4 days of immersion in water (CBR-4days) of the untreated (natural) clay soil, the soil treated with $6 \%$ pozzolana + lime binder (PLB), and the soil treated with $4 \%$ ordinary Portland cement (OPC)

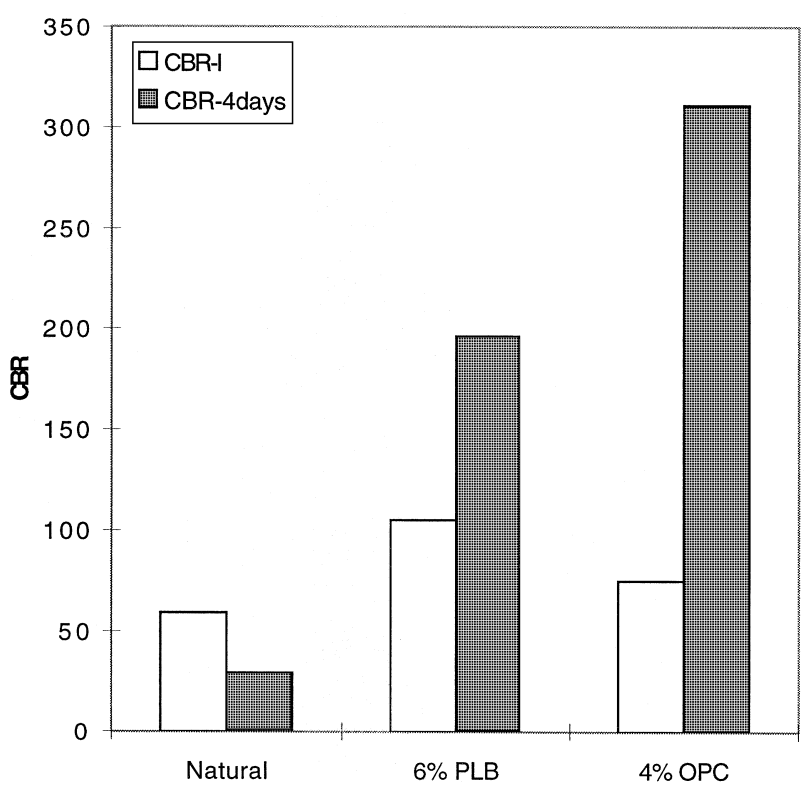

Fig. 6. Immediate Californian Bearing Ratio (CBR-I) and Californian Bearing Ratio after 4 days of immersion in water (CBR-4days) of the untreated (natural) clayous gravel, the clayous gravel treated with $6 \%$ pozzolana + lime binder (PLB), and the clayous gravel treated with $4 \%$ ordinary Portland cement (OPC).

(CBR-4days) for the natural clay soil (untreated), the soil treated with $6 \%$ PLB, and the soil treated with $4 \%$ OPC. All tests were carried on with the optimum soil water content following the standard Proctor method. Treatments with PLB or OPC significantly increase the

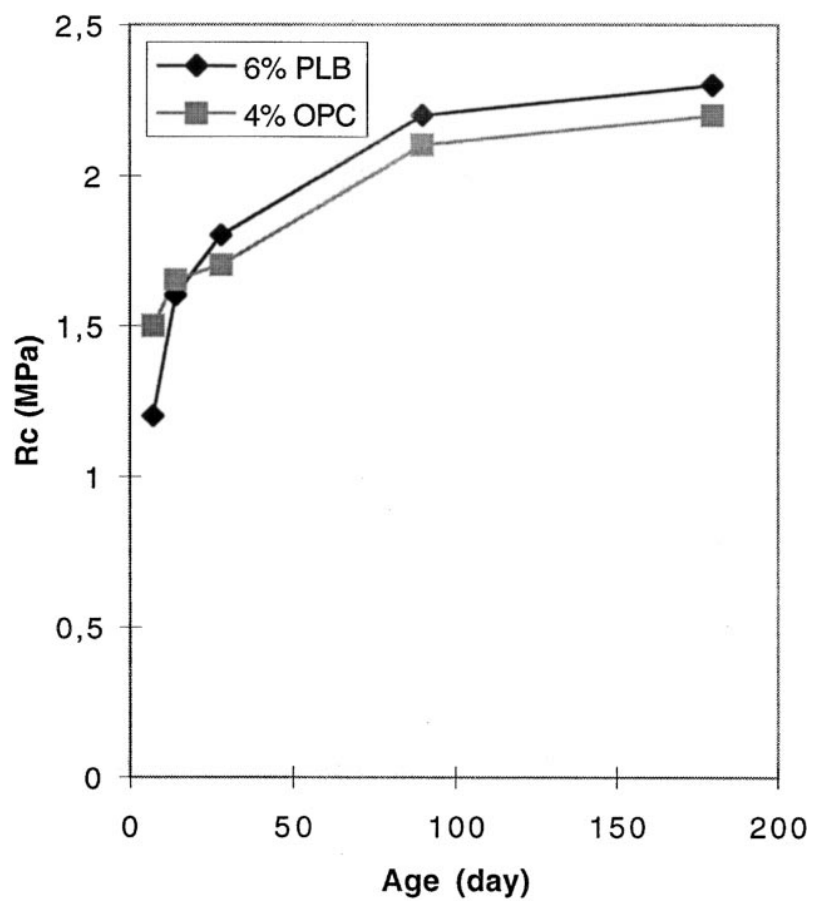

Fig. 7. Compressive strengths of the clay soil at different ages when treated with $6 \%$ pozzolana + lime binder (PLB) or with $4 \%$ ordinary Portland cement (OPC). 
CBR-I. The treatment efficiency is particularly revealed after 4 days of immersion: the natural soil has lost its mechanical properties, when treated soils have much higher CBR than the initial soil. PLB (6\%) exhibit similar efficiency as $4 \%$ OPC.

Similar tests were carried out treating a clayous gravel in the same conditions as the clay soil (6\% PLB or $4 \%$ OPC). Fig. 6 shows higher performances can be reached with this soil than with the clay soil. Again the untreated soil has lost its mechanical resistance after immersion in water. PLB $(6 \%)$ or $4 \%$ OPC both increase the performance of the soil. PLB gives higher CBR-I than OPC; OPC is more efficient than PLB after immersion in water.

These results demonstrate the capacity of pozzolana + lime binders to stabilise soils for road subgrade or base course applications. An equivalence between $6 \%$ PLB and $4 \%$ OPC is stated.

The compressive strengths of the clayous soil treated with $6 \%$ PLB or $4 \%$ OPC have also been measured from $5-\mathrm{cm}$ diameter $10-\mathrm{cm}$ high cylinders; Fig. 7 shows their evolution along time (storage in air at $20^{\circ} \mathrm{C}$ ). After 7 days, $4 \%$ OPC lead to better strengths than $6 \%$ PLB; the compressive strength is already higher than 1 $\mathrm{MPa}$ in both cases, which makes it possible to build houses with several floors. After 14 days, both treatments are equivalent; the PLB then slowly develops higher strengths than OPC. It is classical to observe a slower strengthening with binders elaborated from pozzolana than with OPC. These results demonstrate again an equivalent performance between 6\% PLB and 4\% OPC, and the aptitude of a clay soil stabilised with $6 \%$ PLB to be used as bricks for house building purposes.

\section{Conclusion}

The flash drying and calcining technique involves bringing into operation very rapid combined physical heat and mass transfer phenomena in multiphase suspensions. Numerous precautions are to be taken during design of each element. Nevertheless, the final construction of the unit remains simple boiler making of cyclones and ducts, and results in a compact unit compared with other furnace systems. All requirements for semi-mobility can be fulfilled. An installation including a combustion chamber followed by a separator cyclone (SC) surrounded with one cyclone to dry, one cyclone to preheat and three cyclones to cool down materials has a good thermal balance. It is entirely packaged in four containers: a special 14-m long main one, plus two 20-foot and one 40-foot standard one. It can be moved from one site to another within several days, including stop, disassembling, reassembling and start, without significant material waste.

Six percent of hydraulic binder (elaborated by mixing $70 \%$ pozzolana. out of the unit and 30\% lime) have performances similar to $4 \%$ of ordinary Portland cement.

This type of unit could be a response to the demand for pozzolanic materials of developing countries, where raw clay soils are readily available, but where the little quantities needed and the dispersion in time and place is not suited to the traditional high binder production capacity industry.

\section{Acknowledgements}

The scientific understanding of flash calcination phenomena involved in this process was achieved on the basis of the work of Pr T.W. Davies (School of Engineering, University of Exeter, Exeter EX4 4QF, UK) whom we wish to thank.

\section{References}

[1] Gupta JS, Rao AVR. Production of clay pozzolana by fluidized bed technique. Trans Indian Ceram Soc 1978;37:165-171.

[2] Thatte JP, Patel JK. A new design of plant for manufacturing pozzolana. J Indian Highw 1978;6:14-24.

[3] Davies TW. Density reduction of kaolinite by flash heating. Chem Eng Res Des 1985;63(2):82-88.

[4] Davies TW. Flash dehydroxylation of kaolinite: effect of heating rate on the properties of the calcine. J Mater Sci Lett 1986;5:186-187.

[5] Salvador S, Davies TW. Modelling of combined heating and dehydroxylation of kaolinite particles during flash calcination; production of metakaolin. Proc Adv Mater 1994;9:128-135.

[6] Davies TW. Equipment for the study of flash heating of particle suspensions. High Temp Tech 1984;2(3):141-147.

[7] Meinhold RH, Salvador S, Davies TW, Slade RCT. A comparison of the kinetics of flash calcination of kaolinite in different calciners, Trans. I Chem E, 1994;72:Part A.

[8] Salvador S. Prototyping flash calciners for the manufacture of synthetic pozzolana from kaolinite clay. In: Davies TW, editor. Flash reaction processes, Printed in the Netherlands: Kluwer Academic Publishers. NATO ASI Series, Series E: Applied Science, vol 282, 1995:295-318.

[9] Salvador S. Pozzolanic properties of flash calcined kaolinite; a comparative study with soak calcined products. Cem Concr Res 1995;25(1):102-112.

[10] Salvador S. Production de pouzzolanes de synthèse par calcination flash de sols argileux; étude des produits et conception d'une installation, I'INSA of Toulouse, Thesis, 20 Novembre 1992. 